\title{
PERCEPÇÃO DOS TRANSEUNTES COM RELAÇÃO À CAMINHABILIDADE NAS CALÇADAS DA ORLA DE ATALAIA EM ARACAJU-SE
}

\section{PERCEPTION OF PASSERS-BY WITH REGARD TO WALKABILITY ON THE SIDEWALKS OF THE ATALAIA BEACHFRONT IN ARACAJU-SE}

\author{
F. T. $\operatorname{LEMOS}^{1}$, R. O. CORRÊA ${ }^{1, *}$ and G. D. G. CARVALHO ${ }^{2}$
}

${ }^{1}$ Federal University of Sergipe, Department of Business Administration, São Cristóvão, Sergipe, Brazil

${ }^{2}$ Federal University of Technology - Parana, Department of Industrial Engineering, Ponta Grossa, Parana, Brazil

${ }^{*}$ Corresponding author. Federal University of Sergipe, Department of Business Administration, São Cristóvão, Sergipe, Brazil, Phone: +55 79 $3194-6600$ e-mail rubia.ufs@gmail.com (R.O.Corrêa).

\begin{tabular}{|c|}
\hline A R T I C L I N F O \\
\hline $\begin{array}{l}\text { Article history: } \\
\text { Received 2019-12-03 } \\
\text { Accepted 2020-01-03 } \\
\text { Available online 2020-12-20 }\end{array}$ \\
\hline $\begin{array}{l}\text { pa lavras-chave } \\
\text { Calçadas } \\
\text { Caminhabilidade } \\
\text { GestãoPública } \\
\text { Qualidade }\end{array}$ \\
\hline $\begin{array}{l}\text { keywords} \\
\text { Sidewalks } \\
\text { Walkability } \\
\text { Public administration } \\
\text { Quality }\end{array}$ \\
\hline
\end{tabular}

\section{A B S T R A C T}

The present study aimed to analyze the walkability in the sidewalks of Atalaia, in Aracaju-SE. This research had a descriptive nature and was characterized as a survey. In its approach, it was classified as a quantitative study. The sample was composed of 140 individuals that were present in the beachfront of Atalaia, being classified as non-probabilistic by accessibility. The questionnaire was defined as the instrument of data collection, which was formed by thirteen questions that were evaluated in a seven-point Likert scale. Data analysis revealed that, among the factors surveyed, the infrastructure of the sidewalks of Atalaia was highlighted as the worst evaluated item. The amount of ramps along the route was also another poorly evaluated aspect. However, the walkability was not usually hampered by the width of the sidewalks or the presence of obstacles. The illumination of the sidewalks of the Atalaia waterfront was seen as satisfactory. With regard to the comfort aspect provided by walking on these sidewalks, the respondents highlighted it in a positive way. In opposition to this, the sense of security was assessed in a negative way.

\footnotetext{
R E S U M O

O presente estudo objetivou analisar a caminhabilidade nas calçadas da orla de Atalaia, em Aracaju-SE. Pesquisa de natureza descritiva, e em relação aos procedimentos foi caracterizada como um levantamento (survey). Em sua abordagem, classificou-se como um estudo quantitativo. A amostra do trabalho foi composta por 140 indivíduos que se faziam presentes na orla de Atalaia, sendo classificada como não probabilística por acessibilidade. O questionário foi definido como o instrumento de coleta de dados. Esse foi formado por treze perguntas fechadas, as quais foram avaliadas com o auxílio da escala Likert de sete pontos. A análise dos dados revelou que, dentre os fatores pesquisados, a infraestrutura das calçadas da orla de Atalaia destacou-se como o item de pior avaliação. A quantidade de rampas ao longo do trajeto também foi outro aspecto mal avaliado. No entanto, a caminhabilidade não foi dificultada pela largura das calçadas ou presença de obstáculos. A iluminação das calçadas da orla de Atalaia foi vista como satisfatória. Com relação ao aspecto conforto proporcionado pelo ato de caminhar nas referidas calçadas, os respondentes o destacaram de forma positiva. Em oposição a isso, a sensação de segurança foi avaliada de maneira negativa.
} 


\section{INTRODUÇ̃̃̃O}

Nos últimos anos, a mobilidade urbana vem sendo ponto crucial de referência em estudos nos centros metropolitanos (Santos; Nora, 2015). A caminhabilidade está além do simples processo de caminhar, é vista como um parâmetro capaz de mensurar a satisfação dos transeuntes com relação a forma como está sendo planejada e gerida a mobilidade em uma cidade (Ghidini, 2010). Assim, aspectos como fluidez, conforto e segurança entram no contexto da caminhabilidade (Gold, 2003).

D’Almeida (2017) afirma que as cidades brasileiras, em geral, não apresentam ruas planejadas, estruturadas e em perfeitas condições para receber o pedestre, assim não incentivam as viagens a pé. $\mathrm{O}$ exposto sugere a necessidade de os gestores públicos formularem políticas para enfrentar barreiras que dificultam a caminhabilidade. Nestas políticas devem ser considerados aspectos como: estratégias para melhor sinalização, iluminação, conforto, entre outras condições que favorecem a caminhabilidade. Na presença desse cenário, o estudo se justifica frente à necessidade da participação efetiva da gestão pública na garantia dos requisitos básicos que proporcionam a qualidade e, consequentemente, o interesse do pedestre em praticar a caminhabilidade.

Ressalva-se que, a caminhabilidade é uma temática relativamente conhecida, no entanto, é pouco investigada em seus aspectos de gestão urbana (Azevedo, 2008). Diante da gama variada de espaços onde seria possível estudar a temática aqui apresentada, este estudo limitou-se a investigar a gestão da caminhabilidade das calçadas da orla de Atalaia em Aracaju, capital do estado de Sergipe. Esta análise foi feita sob a ótica dos transeuntes, pois acredita-se que estes possuem know-how para falar da citada localidade, a qual é bastante conhecida e frequentada pelos moradores do estado de uma forma ampla.

A escolha da localidade se deu por se tratar de uma região onde existe um fluxo grande de pessoas que praticam atividades físicas, caminhadas diárias ou transitam simplesmente para desfrutar das suas atrações de lazer. Além disso, a orla de Atalaia é um dos principais "cartões postais" da cidade de Aracaju, recebe um número expressivo de turistas que transitam pelas suas calçadas e tendem a qualificar a cidade com base na infraestrutura dos pontos turísticos por onde passam. Sendo, assim, indispensável que estas calçadas estejam em condições favoráveis para uso.

\section{REFERENCIAL TEÓRICO}

\subsection{Caminhabilidade}

$\mathrm{O}$ ato de andar a pé é um dos meios mais significantes de se locomover nas vias urbanas, pois se trata de uma atividade que, se não for feita como forma de opção, pode ser como complementação de um trajeto realizado por um transporte motorizado coletivo, além de ser muito adotada em cidades de porte menor (Azevedo, 2008). Caminhar é a maneira de deslocamento mais saudável, natural, econômica e limpa quando há necessidade de deslocamentos em curtos trajetos (Marques; Batistela, 2016).
Muitas vezes, o termo "caminhabilidade" é limitado ao conceito de caminhar. No entanto, caminhar é apenas o elemento inicial do processo. De modo geral, as cidades não apresentam ruas planejadas, estruturadas e em perfeitas condições para receber o pedestre, não favorecendo essa prática de deslocamento (D’almeida, 2017). É necessário haver uma preocupação maior com a relação que o pedestre tem com o espaço físico. Isso perpassa pelo estabelecimento de conexões e adaptações em ruas que possibilitem um acesso mais prático (Marques; Batistela, 2016). De forma ampla, Rodrigues et al. (2014) indicam ainda a providência de estudos orientados ao conhecimento das maiores necessidades e dificuldades que os pedestres possuem cotidianamente para maximizar as chances de políticas públicas bem-sucedidas. Para isso, é importante que a gestão pública compreenda a forma de percepção dos pedestres em relação à condição da caminhabilidade ofertada, mesmo que esses não tenham o conhecimento técnico (Pereira; 2013, p 39).

A caminhabilidade pode ser analisada através de indicadores que podem medir o grau de conforto e motivação para caminhar em um determinado espaço. Neste cenário, o termo "desenho urbano" vem ganhando importância diante da reforma de ambientes construídos com intuito de facilitar a caminhabilidade. Para Rodrigues (2013), o desenho urbano diz respeito a rede de caminhos, o comprimento e a quantidade de itinerários entre dois pontos geradores de viagens. Seu grande propósito consiste em facilitar a caminhada e a geração de viagens a pé. Neste cenário, as calçadas são itens do desenho urbano bastante importantes. É possível obter resultados positivos com a implantação de calçadas bem planejadas, a exemplo da diminuição expressiva de frotas motorizadas e o aumento significativo de pedestres nas vias caminháveis. Essa última resultante traz consigo alguns benefícios à própria cidade, principalmente a maior circulação de dinheiro através do estimulo que essa ação incorpora à economia da cidade (Gonçalves; Fonseca; Cardoso, 2017).

Estudos sobre o tema no Brasil encontram-se numa fase inicial de exploração. Por exemplo, Silva et al. (2010) objetivaram propiciar valor ao planejamento municipal da mobilidade feita a pé nas cidades avaliadas: Aracaju e Salvador. Para tanto, verificaram a qualidade da caminhabilidade em alguns trechos das citadas cidades. Em Salvador, os trechos avaliados têm alto nível de atratividade através do uso do solo lindeiro e das relações sociais que ali são permitidas, porém, tem baixo nível de segurança. Portanto, certa interferência na estrutura física seria uma estratégia importante para a promoção de qualidade no processo de caminhabilidade. Já em Aracaju, as maiores notas foram atribuídas à atratividade por conta do comércio local. As menores notas foram atribuídas às questões de proteção de trafego e a inexistência de mobiliário urbano. Contudo, para que essa rota seja mais caminhável, os autores sugeriram a redução do tráfego de veículos e o alargamento de calçadas.

Barretto e Gislon (2013) buscaram registrar a percepção de diferentes atores sociais sobre o processo de revitalização da rua Vidal Ramos, no centro histórico da cidade de Florianópolis. Como resultado, o processo de revitalização gerou boas condições de caminhabilidade, independente da função 
comercial que é atribuída à rua; aspecto este que muitas áreas urbanas não possibilitam. Barros, Martinez e Viegas (2015) verificaram que cinco variáveis apresentaram 'impacto muito negativo' na caminhabilidade percebida por brasileiros e portugueses: ausência de iluminação, ausência de calçada, calçadas com muitos buracos, carros estacionados na calçada e ausência de faixa de pedestres. Barbosa (2016) avaliou por meio de 8 pontos críticos a caminhabilidade no entorno das estações do metrô de Salvador (Densidade; Uso do Solo; Largura da Calçada; Condições do Piso; Proteção Intempéries, Mobiliário Urbano; Segurança Travessia e Proteção do Tráfego), a qual apresentou um nível geral regular, onde a qualidade dos percursos não é muito adequada para o deslocamento a pé. Lins (2015) propôs uma ferramenta que enquadra as normas da ABNT NBR 9050 na formação das calçadas e avaliou a caminhabilidade na Av. Conselheiro Aguiar da cidade do Recife, que não obteve um bom resultado, apenas $26,7 \%$ da nota máxima.

Marques e Batistela (2016) propõem uma avaliação da qualidade do quesito caminhabilidade, focado em compreender as características ambientais, espaciais e funcionais, além da percepção dos pedestres. Para a coleta de dados, foi utilizado o Índice de Qualidade Ambiental Percebida, que é dividido em dois formulários de questões fechadas e respostas escaladas. Os autores concluíram que existe um padrão de insegurança em relação aos pedestres na zona norte de São Paulo gerado em alguns horários por causa da ociosidade do espaço público. A caminhabilidade foi notada, com melhor fluidez, no canteiro central da avenida Engenheiro Caetano Álvares, por ser o local com mais qualidade ambiental e estrutural.

\subsection{Calçadas e Condições de Fluxo de Pedestres}

As calçadas são áreas de interações coletivas no âmbito público, que garantem o direito de ir e vir a qualquer cidadão brasileiro (Melo et al., 2016). Salienta-se que este trabalho se baseia na Lei Municipal n 4,867 de 29 de março de 2017 que institui padrão de analogia entre calçadas e passeios públicos (Câmara..., 2017). Cunha e Helvecio (2013, p 10) afirmam que "a calçada é o primeiro degrau da cidadania urbana", portanto, quando esse espaço público não é disponibilizado com mínimo critério de qualidade, as pessoas perdem a possibilidade de desfrutar as oportunidades que a cidade oferece diante de inúmeros obstáculos que por muitas vezes limitam o direito de ser cidadão. Dias, Silva e Pereira (2012) também tratam a questão da falta de cidadania urbana como um processo de "desumanização das calçadas".

Sabe-se que fatores físicos e/ou ambientais influenciam na qualidade das calçadas, induzindo o pedestre a querer se deslocar ou não por esses espaços (Farias, 2015). Cavalaro, Angelis e Lemos (2013) destacam a fluidez, o conforto e a segurança, como fatores que qualificam a caminhada positivamente ou negativamente.

Em Aracaju, cidade em que está sendo realizado esse estudo, foi discutida e sancionada, em 2013, a lei municipal $\mathrm{n}^{\circ}$ 4.444 , onde se concentravam todos os requisitos para uma melhoria continua na qualidade das calçadas de Aracaju e no seu acesso eficiente (Barbosa; Theobald, 2016). Melo et al. (2016) retrataram a realidade das calçadas aracajuanas, expondo que elas são apertadas, possuindo em média até dois metros de largura e, além disso, relataram o déficit de propostas que visam melhorar o acesso ao espaço público, situação perceptível em âmbito nacional.
No que diz respeito à responsabilização sobre a manutenção e construção de calçadas, é importante frisar a existência de quatro tipos: calçadas residenciais e comerciais, de responsabilidade dos proprietários; e calçadas não residenciais e não comerciais, de responsabilidade pública. Frisa-se aqui que, nesse estudo, estão sendo analisadas calçadas localizadas em áreas não residenciais e não comerciais. Segundo Melo et al. (2016), a preservação e o ajustamento desse tipo de calçada são de responsabilidade do poder público, como aqueles presentes em parques, largos e praças.

O direito de ser cidadão é algo complexo e deve ser considerado como elemento fundamental de condição na qualidade do sistema urbano e, diante disso, os problemas que envolvem a acessibilidade no Brasil podem ter um aperfeiçoamento no seu contexto através da parceria entre o público e o privado, ou seja, o Estado precisa ter uma atuação dinâmica e a população deve incentivar sempre as boas condições e o zelo do passeio público (Nunes; Rodrigues, 2017). Obstáculos que dificultam ou impedem a locomoção de pedestres, especialmente junto àqueles que possuem limitações físicas ou mobilidade reduzidas, justificam a necessidade de se priorizar as questões relacionadas à acessibilidade no Brasil (Caldas; Moreira; Sposto, 2015). Sabe-se que uma política de acessibilidade adequada possibilita que pessoas portadoras de deficiência ou com mobilidade reduzida façam uso, de forma segura e autônoma, dos espaços, mobiliários e equipamentos urbanos, bem como, das edificações, dos transportes e dos meios de comunicação de uma região (Lamônica et al., 2008).

De acordo com Silva (2013), existem leis federais que contemplam os direitos das pessoas com algum tipo de deficiência. A acessibilidade se efetiva e é regulamentada pela lei $n^{\circ} 10.098 / 2000$, que dispõe de diretrizes legais que auxiliam a adaptação do deficiente ou da pessoa com mobilidade reduzida, através do processo que Sloboja (2014, p. 13) entende como "adequação de espaços urbanos como portas de locais públicos, rampas de acesso, sinalização visual, [...]meios de comunicação e de transporte, [...] as regras de construção e reforma". A Norma Brasileira 9050/2004 serve como um guia de diretrizes que conecta os espaços públicos à elementos de acessibilidade, direcionando os esforços na adaptação do maior número possível de pedestres nas vias em que circulam, de modo seguro e confortável, ou seja, a NBR 9050 é considerada o requisito para critérios de acessibilidade (ABNT, 2015).

Para Poleza (2010, p. 42), as "calçadas plenamente acessíveis significam conforto de uso, através do piso regular e antiderrapante, faixa livre, de serviço e de acesso". Melo et al. (2016) retratam que é necessário existir uma organização em faixas para poder atender outros propósitos que competem às calçadas, além de promover o fluxo de pedestres, como a adaptação dos mobiliários urbanos e vegetação. A quantidade de faixas em uma calçada depende do seu tamanho. Para Carletto et al. (2016), as três faixas são obrigatórias em calçadas que ultrapassam dois metros de largura. Nos casos em que isso não acontece, é necessário que a administração pública valorize a faixa de fluxo de pedestres e utilize as normas reguladoras para direcionar melhor o espaço público.

\section{As faixas aqui citadas são, a seguir, melhor detalhadas:}

a) Faixa de Serviço - lugar na calçada que é permitida a presença de itens que podem ser utilizados pelas pessoas ou servir como estrutura das vias urbanas, como postes de iluminação, bancos, lixeiras, sinalização de trânsito, entre outros 
(Xavier, 2012).

b) Faixa Livre - essa faixa deve ser o espaço utilizado por qualquer pessoa, seja ela deficiente ou não, pois se trata de um espaço exclusivamente destinado para o fluxo constante de pessoas (Melo et al., 2016). Por ser tratar de uma zona indispensável a todas as calçadas, a faixa livre deve ser nivelada, não possuindo discrepância no seu segmento, e deve obedecer ao critério mínimo de 1,20 metros de largura (Carletto et al., 2016), além de ter largura proporcional ao fluxo de pedestres, conforme a norma da ABNT 9050 (Melo et al., 2016).

c) Faixa de Acesso - onde se localiza todo material móvel, como cadeiras e mesas de estabelecimentos, assim como a rampa que possibilita a entrada do veículo e a utilização de plantas (Carletto et al., 2016).

\section{METODOLOGIA}

A presente pesquisa se enquadra como descritiva, a qual teve como objetivo primordial a descrição das características de determinada população ou fenômeno (Gil,2010); no presente caso, a caminhabilidade nas calçadas da orla de Atalaia em Aracaju-SE.

Com relação aos procedimentos, esse estudo caracterizou-se como um levantamento (survey), que "busca informação diretamente com um grupo de interesse a respeito dos dados que se deseja obter" (Gerhardt; Silveira, 2009, p. 39). Em sua abordagem, classifica-se como uma pesquisa quantitativa, uma vez que se utilizou da quantificação para coletar e tratar as informações que subsidiaram o estudo em questão.

A amostra deste trabalho foi composta por 140 transeuntes. Esta amostra foi classificada como da espécie não probabilística por acessibilidade. Para obtenção dos dados, foi elaborado 1 (um) questionário contendo 13 (treze) perguntas fechadas (Tabela 1). Uma escala de Likert de 7 pontos foi utilizada nesta pesquisa, assim os respondentes expressavam seus graus de concordância com os indicadores vinculados às variáveis do estudo. Frise-se que os questionários foram aplicados em dias alternados e com a presença de um pesquisador. A coleta de dados foi obtida junto às pessoas que transitam (residentes em Sergipe e turistas) pelas calçadas da orla de Atalaia, em Aracaju-SE.

A análise de dados "é o processo de formação de sentido além dos dados, e esta formação se dá consolidando, limitando e interpretando o que as pessoas disseram e o que o pesquisador viu e leu" (Teixeira, 2003, p.191). Assim, os dados do presente estudo foram tabulados com o auxílio do programa StatisticalPackage for Social Science - SPSS, possibilitando uma análise descritiva deles e foram analisados com base nas frequências (absolutas, relativas e acumuladas), média e desvio padrão obtidos pelas respostas das questões objetivas.

\section{RESULTADOS}

\subsection{Perfil da Amostra}

No que diz respeito à questão gênero, revelou-se uma pequena superioridade de pessoas do sexo masculino participando desta pesquisa. Dentre os transeuntes inquiridos $57,1 \%$ são do sexo masculino e $42,9 \%$ do sexo feminino. Dados fornecidos pelo Censo (IBGE, 2010) revelam que a população brasileira é composta por 190.755 .799 habitantes. Sabe-se que $51 \%$ (97.348.809) desses habitantes são do sexo feminino e 49\% (93.406.990) do sexo masculino. Percebe-se uma distribuição bastante equilibrada da população brasileira com relação ao aspecto gênero. Tal constatação deve ter elevado as chances de capturar, de forma equilibrada, quantidades de homens e mulheres para responderem aos questionamentos deste estudo.

Em relação ao estado civil dos respondentes, é possível averiguar que $74,3 \%$ dos inquiridos se definiram como solteiros. Os demais participantes desta pesquisa se autodeclararam casados $(21,4 \%)$ e divorciados $(4,3 \%)$. De acordo com o Censo (IBGE, 2010), mais da metade da população brasileira (89.653.403 habitantes) é constituída por solteiros. No mais, na orla de Atalaia, diante de varias opções de lazer e descontração, predispõe a presença desse tipo de público, bem como de pessoas jovens.

Percebeu-se um reduzido número de pessoas que detém apenas nível fundamental $(2,1 \%)$. Entretanto, o Brasil é um país que possui uma população pouco escolarizada, $43 \%$ (81.386.577) dela é formada por pessoas sem instrução ou com apenas o nível fundamental incompleto (IBGE, 2010). Na amostra pesquisada tem-se ainda pessoas que declararam possuir ensino médio completo $(27,9 \%)$ e outras que revelaram estar cursando o ensino superior (40\%). Dentre os respondentes, $24,3 \%$ possuem ensino superior e $5,7 \%$ pós-graduação.

Em média, os inquiridos possuem aproximadamente 28 anos. Adicionalmente, em média, os transeuntes usufruem das alçadas da orla de Atalaia aproximadamente 3 (três) vezes por semana. Foi observado também que os valores em torno da média não oscilaram de forma significativa, visto que o desvio padrão acusou um valor baixo $(1,7)$.

Observou-se que a atividade esportiva é a motivação de destaque que justifica a utilização das calçadas da orla de Atalaia por parte de muitos dos entrevistados (45\%). Atividades relacionadas ao lazer também foram outro motivo salientado $(28,6 \%)$. A prática do turismo foi alegada como motivo principal por $15,7 \%$ dos respondentes. Já 7,9\% dos inquiridos utilizam-se com frequência das calçadas pesquisadas, pois essas fazem parte do seu trajeto para o trabalho. Apenas 2,9\% afirmaram que se utilizam das calçadas para usufruírem dos pontos de ônibus existentes na região.

\subsection{Percepção da Caminhabilidade}

A Tabela 1 apresenta os resultados gerais em termos de média e desvio padrão da percepção da caminhabilidade das calçadas na orla de Atalaia, Aracaju-SE, com base na amostra de 140 transeuntes.

Diante da afirmativa 1 "Ao praticar minhas atividades nas calçadas da orla de Atalaia não visualizo irregularidades na infraestrutura do calçamento, ou seja, presença de buracos, montinhos e pedras soltas", em média, os respondentes deram nota 2,3 para essa questão, sinalizando que discordam da afirmativa. Isso implica em insatisfação com relação a infraestrutura das calçadas. O desvio padrão $(1,4)$ sinaliza que as notam atribuídas a esse item não oscilaram muito em torno da média.

Com relação à afirmativa 2: “As calçadas da orla de Atalaia possuem uma largura satisfatória que possibilita a passagem de pessoas e cadeirantes", notou-se uma média no valor de 5,7, sinalizando que no geral os respondentes concordam em parte com a afirmativa. Isso implica em satisfação parcial com relação a largura das calçadas da orla de Atalaia. O desvio padrão $(1,5)$ sinaliza que as notam atribuídas a esse item não oscilaram 
muito em torno da média. A satisfação parcial, representada pela média nessa afirmativa, pode ser justificada pelo fato das calçadas da orla de Atalaia não possuírem uma padronização da largura em todo o seu trajeto.

Tabela 1 - Percepção de caminhabilidade.

Ao praticar minhas atividades nas calçadas

da orla de Atalaia nao visualizo

1 irregularidades na infraestrutura do calçamento, ou seja, presença de buracos, "montinhos" e pedras soltas.

As calçadas da orla de Atalaia possuem

2 uma largura satisfatória que possibilita a passagem de pessoas e cadeirantes As rampas de acesso às calçadas da orla de

3 Atalaia estão presentes em todo o seu trajeto As rampas de acesso às calçadas da Orla

4 de Atalaia estão alinhadas com as faixas de $\quad 4,4 \quad 1,7$ pedestres

As rampas de acesso às calçadas da Orla

5 de Atalaia possuem inclinação adequada e não oferece risco aos cadeirantes Nunca tive minhas atividades dificultadas

6 ou limitadas nas calçadas da Orla de

6 Atalaia por obstáculos, a exemplo de postes, cestas de lixo, carros estacionados A iluminação das caçadas da Orla de

7 Atalaia dá condições ao pedestre de praticar suas atividades sem oferecer er riscos.

As calçadas da Orla de Atalaia são

8 bastante arborizadas, possuem canteiros de $\quad 6,0 \quad 1,1$ plantas e flores

É possível encontrar nas calçadas da Orla

9 de Atalaia bancos e lugares sombreados para descanso.

As calçadas da Orla de Atalaia são

10 sinalizadas de forma satisfatória por meio das faixas de pedestres, semáforos, ciclovias e placas de orientação.

Sinto-me seguro ao caminhar pelas

11 calçadas da orla de Atalaia, diante da presença de constantes rondas policiais. Sinto-me seguro ao caminhar pelas

12 calçadas da orla de Atalaia, diante da presença de postos policiais em todo trajeto.

Nas calçadas da Orla de Atalaia existe piso

13 tátil e semáforos especiais com sinalizadores sonoros para deficientes visuais.

Fonte: os autores.

Frente à afirmativa 3: "As rampas de acesso às calçadas da orla de Atalaia estão presentes em todo o seu trajeto", foi computada uma média de 3,7 pontos. Isso revelou que no geral os entrevistados discordam pouco da afirmação. Já em termos de desvio padrão $(1,6)$ não houve grandes oscilações de valores em torno da média.
Expostos à afirmativa 4: "As rampas de acesso às calçadas da Orla de Atalaia estão alinhadas com as faixas de pedestres", verificouse 4,4 pontos de média para essa declaração. Isso implica dizer que no geral existe indiferença (nem concordância, nem discordância coma a afirmativa) dos respondentes em relação a esse aspecto. $\mathrm{O}$ desvio padrão baixo $(1,7)$ descartam valores extremos a média.

Frente à afirmação 5 "As rampas de acesso às calçadas da Orla de Atalaia possuem inclinação adequada e não oferece risco aos cadeirantes", encontrou-se na média $(4,1)$ valor que revelou indiferença dos respondentes em relação a frase exposta. $\mathrm{O}$ desvio padrão $(1,4)$ sinalizou uma baixa dispersão dos dados em torno da média.

Ao serem expostos à seguinte afirmação 6: "Nunca tive minhas atividades dificultadas ou limitadas nas calçadas da Orla de Atalaia por obstáculos, a exemplo de postes, cestas de lixo, carros estacionados", em média os respondentes deram nota 5,5 para essa questão, sinalizando que concordam em parte com a afirmativa. O desvio padrão $(1,9)$ sinaliza que as notam atribuídas a esse item não oscilaram muito em torno da média. Essa avaliação positiva sinalizou que obstáculos não costumam ser percebidos pelos inquiridos. Acredita-se que a largura de alguns dos trechos da região pesquisada pode minimizar problemas vinculados a possíveis obstáculos ali presentes.

Diante da afirmativa 7 "A iluminação das caçadas da Orla de Atalaia dá condições ao pedestre de praticar suas atividades sem oferecer riscos", em média, os respondentes atribuíram nota 5,6 para esse quesito, representando pouca concordância com o item e satisfação parcial com a situação observada.. Como o desvio padrão foi de $(1,6)$, constatou-se que não há um grande distanciamento das notas apresentadas em torno da nota média.

Diante da afirmativa 8 "As calçadas da Orla de Atalaia são bastante arborizadas, possuem canteiros de plantas e flores", os respondentes concordaram bastante com o fato abordado, isso refletiu na média $(6,0)$ obtida. Já o desvio padrão $(1,1)$ demonstrou que as notas variam pouco em torno da média. Isto é, as notas estão à vista da tendência central.

Para a afirmativa 9 "É possível encontrar nas calçadas da Orla de Atalaia bancos e lugares sombreados para descanso", os respondentes, em média, deram nota 5,0, significando pouca concordância com o item exposto. Sendo assim, em complemento do item anterior, avaliou-se o conforto para a caminhabilidade como um aspecto consideravelmente bom na Orla de Atalaia. O desvio padrão $(1,5)$ significa que não houve grande distanciamento das notas em relação à média.

Em relação à afirmativa 10 "As calçadas da orla de Atalaia são sinalizadas de forma satisfatória por meio das faixas de pedestres, semáforos, ciclovias e placas de orientação", através da média $(4,6)$, percebeu-se que os respondentes demonstraram indiferença diante da questão, nem concordam nem discordam com a afirmativa. O desvio padrão $(1,6)$ revelou uma pequena variação das notas frente à média geral.

Ao analisar as questões voltadas para o aspecto de segurança, inicialmente, os respondentes avaliaram a afirmativa 11: "Sinto-me seguro ao caminhar pelas calçadas da orla de Atalaia, diante da presença de constantes rondas policiais". As notas a seguir apresentadas mostram insatisfação dos entrevistados com relação a presença das rondas policiais. A média $(3,0)$ mostra que os respondentes discordam um pouco da declaração. Diante do desvio padrão $(1,3)$, notou-se que as notas sugeridas giram em torno da média.

Em seguida, os inqueridos avaliaram a afirmação 12: "Sinto-me seguro ao caminhar pelas calçadas da orla de Atalaia, diante da presença de postos policiais em todo trajeto". Os respondentes, em média, concederam nota 2,7 por discordarem 
muito da afirmativa. O desvio padrão $(1,1)$ sinalizou que não houve uma grande variabilidade de notas em torno da média.

\section{CONSIDERAÇÕES FINAIS}

Esta pesquisa resultou da opinião de 140 transeuntes presentes na orla de Atalaia. A amostra revelou-se equilibrada com relação ao quantitativo de homens e mulheres respondentes. Dentre os inquiridos $57,1 \%$ foram do sexo masculino e $42,9 \%$ do feminino. Em média, os respondentes possuem aproximadamente 28 anos. A maioria (70\%) não possui ensino superior completo. Em média, esses transeuntes usufruem dessas calçadas aproximadamente três vezes por semana. A atividade esportiva é a motivação maior que leva os transeuntes a se utilizarem das calçadas referidas (45\%).

Num segundo momento foram averiguadas as condições que desfavorecem a caminhabilidade das calçadas da orla de Atalaia. Dentre os fatores pesquisados, a infraestrutura das calçadas destacou-se como o item de pior avaliação. A quantidade de rampas ao longo do trajeto também foi outro aspecto mal avaliado. Os respondentes foram, na média, indiferentes com relação aos aspectos: a) as rampas e seu devido alinhamento com a faixa de pedestre; e b) a inclinação adequada das rampas. Essas notas sinalizam, de forma ampla, a ausência de satisfação por parte dos transeuntes diante das questões que poderiam, se adequadas, facilitar o ato de caminhar nas calçadas da orla de Atalaia.

No entanto, a caminhabilidade não costuma ser dificultada pela largura das calçadas ou presença de obstáculos, a exemplo de postes, cesta de lixo, carros estacionados. Tal afirmação deriva das médias atribuídas pelos respondentes, todas acima de 5 pontos. Assim, os transeuntes inquiridos mostraram-se satisfeitos, em parte, com o cenário.

Neste estudo ainda foram verificadas as estratégias em prol da adequada sinalização, iluminação e segurança para caminhabilidade nas calçadas da orla de Atalaia. Diante dos achados, no que consiste à iluminação, verificou-se uma avaliação satisfatória, resultando numa média de 5,6. Em oposição a isso, a sensação de segurança foi avaliada de maneira negativa diante dos fatores: a presença de postos policiais e rondas policiais constantes nas calçadas da orla de Atalaia. Os respondentes, por sua vez, foram indiferentes para com as estratégias de sinalização das calçadas sob análise. A apreciação dos dados sinalizou a necessidade urgente de planejar estratégias que viabilizem principalmente a segurança das pessoas, através de reforço policial ao longo de todo trajeto da orla, para que com isso as pessoas possam sentir-se mais seguras a ponto de incentivar a caminhabilidade.

A melhoria na sinalização das calçadas aqui averiguadas também se faz necessária. Assim, é possível fazer investimentos para aumentar os números de faixas de pedestres na totalidade do trajeto e providenciar os devidos reparos na pintura das faixas para que melhore a sua visualização e facilite o fluxo dos pedestres que queiram se deslocar para a orla. Seria interessante também, definir um calendário de manutenção preventiva e constante dos postes públicos, para que futuras avaliações a respeito da iluminação continuem positivas.

A pesquisa ainda investigou as ações desenvolvidas em prol da promoção do conforto nas calçadas da orla de Atalaia. Observou-se que o conforto é proporcionado através da existência da arborização, com canteiros de plantas e flores, assim como na presença de bancos e lugares sombreados para descanso. $\mathrm{O}$ aspecto conforto dos transeuntes foi bem avaliado, uma vez que a arborização e a possibilidade de descanso diante da presença de bancos e lugares sombreados tiveram médias superiores a 5. Sendo assim, as ações públicas em prol do conforto nas calçadas da orla de Atalaia foram retratadas como um aspecto consideravelmente bom para a caminhabilidade.

Diante do desfecho dessa pesquisa e da contribuição que lhe é designada, identificaram-se diversos pontos críticos que prejudicam a qualidade e acessibilidade intrínsecas à caminhabilidade das calçadas da orla de Atalaia e que estimulam a definição de sugestões de melhorias. As recomendações à gestão pública são as seguintes:

a) Orienta-se que sejam feitas as manutenções necessárias na infraestrutura do calçamento das calçadas da orla de Atalaia.

b) Aconselha-se a construção de novas rampas de acesso em todo o trajeto, com menores distanciamentos e sem pontos de barreiras, como se observa principalmente nas entradas dos estacionamentos.

c) Sugere-se a ampliação imediata e constante de rondas policiais em todo trajeto da orla de Atalaia, principalmente no turno noturno onde os índices de assaltos são maiores.

d) Recomenda-se a existência de postos policiais, em pontos estratégicos, dentro da totalidade do trajeto da orla de Atalaia para dar suporte às rondas policiais.

e) Sugere-se a implantação de sistema de câmeras em todo o trajeto da orla de Atalaia, para que o monitoramento dê respaldo ao policiamento e viabilize a segurança eficiente

f) Orienta-se que seja feita a implementação do piso tátil em todo o trajeto e a colocação de semáforos sonoros junto às faixas de pedestres para possibilitar a caminhabilidade também aos deficientes visuais.

g) Aconselha-se a manutenção preventiva dos postes de iluminação, assim como a implantação de novos postes em áreas críticas.

h) Sugere-se o aumento de faixas de pedestres, em todo o trajeto, aliado à implantação de novos semáforos, que facilite a travessia e que possibilite a caminhabilidade ao transeunte sem depender, exclusivamente, da educação no transita.

i) Recomendam-se as placas informativas para direcionar os transeuntes aos seus devidos destinos, já que se trata de um local turístico.

Por fim, propõe-se a expansão dessa temática, para tanto, outros indicadores podem ser incluídos. No mais, novos trechos da orla podem ser averiguados, assim como outras localidades. Sugere-se atenção dos pesquisadores às localidades de movimentação expressiva ou turísticas. Tais estudos irão melhor investigar a qualidade da caminhabilidade em novos trechos da cidade, isso trará à tona os problemas, os pontos positivos e a realidade de forma ampla de outras localidades. 


\section{R E F E R Ê N C I A S}

ABNT - ASSOCIAÇÃO BRASILEIRA DE NORMAS TÉCNICAS. NBR 9050: Acessibilidade a edificações, mobiliário, espaços e equipamentos urbanos. 3 ed. Rio de Janeiro. 2015.

AZEVEDO, Cristiane de Fátima Figueirêdo Gonçalves de. Transporte não motorizado e a mobilidade sustentável: Os deslocamentos a pé na região sudoeste do Recife. 2008. 220 f. Dissertação (Mestrado) - Curso de Engenharia Civil, Universidade Federal de Pernambuco, Recife, 2008.

BARBOSA, Antônio Diego Padilha; THEOBALD, Roberto. Caminhabilidade do trabalhador portador de mobilidade reduzida nas calçadas da cidade de Aracaju: uma análise das áreas centrais e suas possíveis consequências de acidentes de trajeto. Ideias e Inovação, Aracaju, v. 3, n. 1, p.1122, fev. 2016.

BARRETTO, Margarita; GISLON, Jacinta Milanez. O flâneur revisitado: processos de revitalização urbana e caminhabilidade. Revista Hospitalidade, São Paulo, v. X, n. 1, p.54-77, jun. 2013.

BARROS, Ana Paula Borba Gonçalves; MARTÍNEZ, Luis Miguel Garrido; VIEGAS, José Manuel. A caminhabilidade sob a ótica das pessoas: o que promove e o que inibe um deslocamento a pé?. Ur, [s.1.], v. 8, p.94-103, jun. 2015.

CALDAS, Lucas Rosse; MOREIRA, Mirellen Mara; SPOSTO, Rosa Maria. Acessibilidade para pessoas com mobilidade reduzida segundo os requisitos da norma de desempenho: Um estudo de caso para as áreas comuns de edificações habitacionais de Brasília - DF. Revista Eletrônica de Engenharia Civil, [s. 1.], v. 10, n. 2, p.23-28, 21 set. 2015.

CÂMARA MUNICIPAL DE ARACAJU (Município). Lei $n^{\circ}$ 4,867, de 29 de março de 2017. Aracaju, SE, 2017.

CARLETTO, Ana Claudia; CAMBIAGHI, Silvana; FANTINI, Oswaldo Rafael; BENINE, Renato Jaqueta; LORDELLO, Gustavo Magalhães. Cartilha da Calçada Cidadã: Conserve a sua calçada. O respeito ao outro começa na porta da sua casa. Brasil, p. 9-37, 2016.

CAVALARO, Juliana; ANGELIS, Bruno L. D. de; LEMOS, Syntia. Nível de serviço e qualidade das calçadas. II Simpósio de Estudos Urbanos: a dinâmica das cidades e a produção do espaço. Anais... Curitiba, ago. 2013.

CUNHA, Francisco Carneiro da; HELVECIO, Luiz. Calçada: o primeiro degrau da cidadania urbana. Recife: INTG, 2013.

D’ALMEIDA, Ursula Gonçalves. A Caminhabilidade e os Conjuntos Habitacionais Populares: o caso do conjunto Santa Rosa em Campos dos Goytacazes/RJ. I Simpósio Brasileiro Online: Gestão Urbana, [s.1.], abr. 2017.

DIAS, Joaquina Conceição; SILVA, Sandra Maria Batista da; PEREIRA, Aires José. Um estudo sobre as calçadas do bairro São João em Araguaína-TO. Observatorium: Revista Eletrônica de Geografia, Uberlândia, v. 4, n. 11, p.45-61, out. 2012.

FARIAS, Marjorie Maria Abreu Gomes de. A qualidade das calçadas: um estudo de caso da Av. Pres. Epitácio Pessoa -
PB. 2015. 152 f. Dissertação (Mestrado) - Curso de Arquitetura e Urbanismo, Universidade Federal da Paraíba, João Pessoa, 2015.

GERHARDT, Tatiana Engel; SILVEIRA, Denise Tolfo (Org.). Métodos de pesquisa. Porto Alegre: Ed. da UFRGS, 2009. (Educação a Distância, 5).

GIL, Antônio Carlos. Métodos e Técnicas de Pesquisa Social. 6 ed. São Paulo: Atlas 2010.

GHIDINI, Roberto. A caminhabilidade: medida urbana sustentável. Universidade Presbiteriana Mackenzie, São Paulo, 2010 .

GOLD, Philip Anthony. Melhorando as Condições de Caminhada em Calçadas: nota técnica. São Paulo: Gold Projects, 2003.

GONÇALVES, Pedro Henrique; FONSECA, Thalita Pereira da; CARDOSO, Carina Folena. Entraves ao deslocamento pedonal em uma cidade de pequeno porte: os níveis de caminhabilidade na cidade de Goiás-GO. Mix Sustentável, [Santa Catarina], v. 3, n. 2, p.58-66, jan./dez. 2017.

IBGE - INSTITUTO BRASILEIRO DE GEOGRARIA E ESTATÍSTICA. Censo Demográfico, 2010. Disponível em: <http://www.ibge.gov.br>. Acesso em: 20 abr. 2018.

LAMÔNICA, Dionísia Aparecida Cusin; ARAÚJOFILHO, Pedro; SIMOMELLI, Simone Berriel Joaquim; CAETANO, Vera Lígia Santos Butiquiol; REGINA, Márcia Regina Rodrigues; REGIAN, Denise Maria. Acessibilidade em ambiente universitário: identificação de barreiras arquitetônicas no campus da USP de Bauru. Rev. bras. educ. Espec., v. 14, n. 2, p.177-188, ago. 2008.

LINS, Alane N. J. Mandel. WALKABILITY NO MUNICÍPIO DO RECIFE Soluções para efetivar a adequação das calçadas à norma técnica. Revista Especialize On-line IPOG, Goiânia, v. 1, n. 10, p. 2179-5568, julh. 2015.

MARQUES, Taícia Helena Negrin; BATISTELA, Tatiana Sancevero. Percepção da caminhabilidade no entorno da interseção das Avenidas Engenheiro Caetano Álvares e Imirim. Revista Labverde, São Paulo, v. 12, n. 6, p.151-177, ago. 2016.

MELO, Berenice Andrade de. Projeto Calçada Livre: Juntos por espaços acessíveis. Aracaju, p. 5-45, out. 2016.

NUNES, Rosilene Batista; RODRIGUES, Eubia Andréa. Calçadas Públicas como Fator de Acessibilidade e Mobilidade Urbana na Cidade de Tefé-AM. Perspectiva Geográfica: Campus Marechal Cândido Rondon, [s. 1.], v. 12, n. 17, p.164-180, jul./dez. 2017.

PEREIRA, Maria Manuela Vieira Teixeira. Educação e formação de adultos: reconhecimento, validação e certificação de competências de adultos sem a escolaridade básica obrigatória na região autónoma da madeira. 2013. 457 f. Tese (Doutorado) - Curso de Ciências da Educação, Universidade Nova de Lisboa, Lisboa, 2013.

POLEZA, Marina Macedo. Calçadas urbanas sobre o enfoque dos fatores de fluidez, conforto e segurança. 2010. 60 f. Monografia (Especialização) - Curso de Gestão Técnica do Meio Urbano, Pontifícia Universidade Católica do Paraná, Curitiba, 2010

RODRIGUES, A. R. P. A mobilidade dos pedestres e a 
influência da configuração da rede de caminhos. 2013. Dissertação (Mestrado) - Curso de Engenharia de Transportes, Universidade Federal do Rio de Janeiro, Rio de Janeiro, 2013.

RODRIGUES, André Ricardo Prazeres et al. Indicadores do desenho urbano e sua relação com a propensão a caminhada. Journal Of Transport Literature, [s. 1.], v. 8, n. 3, p.62-88, jul. 2014.

SANTOS, Nilcemara de Souza França; Nora, Angye Cássia. Mobilidade urbana e política pública: uma análise das ações realizadas pelo poder público na cidade de Itabuna, Bahia. In: V Semana do Economista \& V Encontro de Egressos. 2015, Bahia. Anais... Ilhéus, 2015.

SILVA, Cesar Henriques Matos e; RODRIGUES, Marcos Antônio Nunes; GONÇALVES,David Felipe Pinheiro; MONTEIRO, Sueline Santos; SOUZA, André da Silva; BELOSO, Nicholas Alexandre Dourado. Avaliação das condições de caminhabilidade nas areas centrais de Salvador e Aracaju, Brasil. XIV CIU - Congresso Iberoamericano de Urbanismo Taller 6 - Movilidad, accesibilidad y ciudad integrada. 2010 .
SILVA, Tâmara Mirely Silveira. Direito fundamental à acessibilidade no Brasil: Uma revisão narrativa sobre o tema. $5^{\circ}$ Enpac: Encontro de Produção Acadêmico-Científico. 2013, Campina Grande. Anais... Campina Grande, 2013.

SLOBOJA, Rosenilda. A acessibilidade e a inclusão social de deficientes físicos (cadeirantes) nas escolas públicoestaduais de Goioerê: superando as barreiras na educação. 2014. 43 f. Monografia (Especialização) - Curso de Ensino de Ciências, Universidade Tecnológica Federal do Paraná, Medianeira, 2014.

TEIXEIRA, Enise Barth. A Análise de Dados na Pesquisa Científica: importância e desafios em estudos organizacionais. Desenvolvimento em Questão, [s. 1.], v. 1, n. 2, p.177-201, jul./dez. 2003.

XAVIER, Denise. O caminho do pedestre: uma análise dos passeios públicos na cidade de São Paulo. Belas artes, [s. 1.], v. 5, mar. 2012 . 